\title{
A Method to Evaluate Quality of Life of Elderly People Based on
}

\section{Intelligent Wearable Devices}

\author{
Gang Yang ${ }^{1, a}$,Huilin $\mathrm{Mo}^{2, \mathrm{~b}}$,Feifei Yang ${ }^{2, \mathrm{c}}$ and Dongyue $\mathrm{Li}^{1, \mathrm{~d}}$ \\ ${ }^{1}$ School of Electronic Engineering, Xidian University, Xi'an 710071, China \\ ${ }^{2}$ Qian Niu Science and Technology Ltd., Xi'an 710071, China

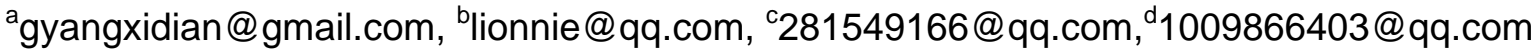

\begin{abstract}
Keywords: Elderly people, monitoring, intelligent wearable device, QOL
\end{abstract}
\begin{abstract}
Aging is a common feature of population structure both at home and abroad. Improving the intelligent level of aging service is meaningful for the development of aging service in the following aspects: 1)enhance the utilization of aging service resources; 2)ensure proper care to be given to elderly people who are in need; 3)enable elderly people to have proper opportunities to maintain their body vitality, to improve their total health and quality of life. Intelligent wearable devices can be used to collect data about the activities, sleeping and basic physiologic function of elderly people in real time, which are analyzed on the cloud platform and a proper description about the real-time life condition of the elders is made swiftly. This evaluation method of life quality based on intelligent wearable devices may take place of the traditional life quality evaluation and become to be one of the standards in monitoring life condition of the elderly, making welfare policies and evaluating the efficiency of aging service.
\end{abstract}

\section{Background}

As the economic and medical level of China have been enhanced a lot in the last decades, the longevity of domestic citizens has also increased. At the same time, the one-child policy which started in the 1980s brings a sharply decline on birth rate. All these bring an increasing ratio of aging population in recent years which was showed to be $10.1 \%$ in the census in 2014[1]. The increasing aging population calls for an expansion of aging service industry. On the other hand, the number of empty-nest families is growing as a result of unbalanced population structure and the migration caused by economic development. There is an relatively shortage of people to take care of the aged family members, which makes it even harder to let aging service cover all the elderly people who are in need. However, most of the aging service industries still stay in labor-intensive state, with lack of professionals on aging service. Most practitioners have heavy working burdens and low payment, which makes a high turnover. The quality of aging service is hard to be assured in the majority of aging service industry, which can hardly make profit normally[2]. There is a trend to use sensors and robots to replace the guardianship and care served by human in future development of aging industry which can definitely enhance the efficiency of aging service.

The basic physiological indexes like blood pressure, blood oxygen concentration, pulse etc., body movement and condition in the room can be recorded using different kinds of sensors[3,4]. Intelligent wearable devices use these sensors to take the work of daily guardianship and upload to share the data collected by sensors with other devices. The application of intelligent wearable devices in perioperative period had a very impressive outcome of significantly decreasing the incidence of postoperative complications[5]. Sensors have been applied in different parts of aging care[6,7]. As different data being collected and analyzed, the function level of elderly people can be 
estimated along with their quality of life(QOL), thus accurate service can be given to people with different function levels in order to reduce waste on aging service resource and to make sure the people in need can be served properly. The accurate aging care also benefits the elderly people as it lets them use the maximum of their abilities in daily life which is important for maintainance of body health and QOL.

The concept 'QOL' was firstly put into use in the USA in 1930s', then it was broadly used in clinical tests, health policy formulation, evaluation of health resource benefits, etc.[8]. The popularization of the concept 'QOL' embodies the change of health evaluation from biomedical model alone to bio-psycho-social model. Aaronson and Meyerrowitz reviewed the development of the concept 'QOL' in the last decade and came up to two central definition: 1)QOL is a multi-dimensional concept including condition of body mechanism, mental and social satisfaction, feelings about health, subjective symptoms about disease; 2)the evaluation of QOL should include subjective evaluation factor supplied by the subject himself. Classical QOL evaluation methods include interview, observation, subjective report, symptomatic type examination, standard questionnaire[9]. Some of the evaluations are designed universally, some are for patients with specific chronic diseases like cancer and cardiovascular diseases and specific groups like teenagers and elders. The evaluation specific for elders can be applied in judging the health condition and mental function, analyzing health economic benefits and evaluating rehabilitation outcomes.

\section{Theoretical Construction}

The theory to use intelligent wearable devices to evaluate QOL is to use sensors to collect physiological indexes, then bring together the data about one's body mechanism, psychological condition and social activities to evaluate one's QOL. The types and ways of collection and analyzation of the data for evaluation are very different from classical evaluation methods. The new evaluation method has the following benefits: 1)the indexes are subjective and accurate; 2)the manpower and material input is sharply decreased; 3)the change of physical health, mental health and QOL are detected with time to form curves which can be simulated with functions thus proper measures can be done to affect the elders' QOL. The biggest difference between the new method and the classical ones is that the classical methods use objective evaluation in most of the questionnaires, however the new method collects data about the subject's customs in daily life activities to deduce the subject's satisfaction degree about life. As the elder people always have some loss on cognitive ability, it may be hard for them to understand the meaning of questions in the evaluation and to describe their condition reasonably. Another downside of classical methods is that elders tend to modify their answers because of their high self-esteem. For the elderly people, the new method evaluates QOL indirectly by analyzation of data about one's daily activities. Most of elderly people in China have the following characters: have to live with one or more chronic diseases; live alone or have to stay alone in the daytime; lack of outdoor activities; lack of sociality ability; have high self-esteem and high psychological sensitivity. A proper evaluation program of QOL for the elders based on intelligent wearable devices should have the following effects:

1. Reform the ways to supply aging service nowadays to enhance quality of service and reduce waste of resources;

2. Make it easy for relatives to know about the life condition of the elders, improve the security for elders to live alone and social support for them;

3. Present a 'Vitality Index' which can be easily understood for elders to evaluate their life condition by themselves. Instead of paying much attention on the physiological indexes like blood pressure and blood sugar, the elders would think more about how to have a healthier life 
style and to gain more happiness in life, which would make them more initiative and vigorous.

\section{Program Design}

\section{I .Reference to classical evaluations}

Based on the theoretical construction, indexes which are highly related with QOL of elderly people as examined by classical evaluations and suitable for intelligent wearable devices to evaluate are chosen and listed as follow.

1. European quality of life 5-dimensions(EQ-5D)

A multi-dimensional evaluation method of QOL which is widely used around the world. The main characteristics of it are easy to use, easy to understand and short time used, which make it suitable for large sample surveys. There are 5 dimensions of this assessment: mobility, self-care, usual activities, pain/discomfort, anxiety/depression.

Yuexia Gao[10] and her colleagues had a household survey to the urban and rural elders in Nantong City, which showed the factors that effected QOL of elders most were social economic factors(education, medical insurance, occupation, income), chronic diseases, sleeping, appetite, leisure life, etc. Another research using EQ-5D argued that chronic diseases, social support, senility, less-educated were the most important factors for elders' health[11].

\section{WHOQOL-100 and WHOQOL-BREF}

Developed by World Health Organization based on the concept of QOL which is broadly used and capable of different culture circumstances. WHOQOL is rarely used in large sample surveys in China, which may be because the assessment is complex with 100 questions. The researches using WHOQOL agreed that the body condition was the biggest influential factor of elders' QOL[12,13]. 3.SF-36

The MOS item short form health survey(SF-36) is developed by Boston Institution of Health in USA based on the Medical Outcomes Study-Short Form(MOS SF) which was developed by Stewartse in 1988. After being transferred into Chinese by Medical College of Zhejiang University in 1991, SF-36 is broadly used in health studies in China.

One study about empty-nest elders in community showed that the main factors about QOL were age, chronic diseases, economic income, whether live with spouse, subjective support[14]. Another study about elders in a nursing home showed that the main factors included age, frequency of physical exercise, chronic disease and self-appraisal of health condition[15].

4.QOL Questionnaire for Chinese Elders

Developed by Institute of Geriatric Medicine of the Chinese Medical Association and show good validity and reliability in many districts of China. The questionnaire includes the following factors: general demographic characteristics(gender, age, ethnic group, occupation, marital status, religion, medical expense, family type, health condition of spouse); factors about life(health condition, customs, economic income, function of daily activities, family atmosphere, housing condition, social communication, psychologic status, satisfaction about life and physical state). A research based on surveys using QOL Questionnaire for Chinese Elders and SF-36 showed a significant relativity between daily activities and QOL scale.

\section{China Health and Retirement Longitudinal Study, CHARLS}

A data pool which collect families and individuals over 45 in China with high quality in order to analyze the problem of the growing population aging in China. One research about QOL and potential influencing factors, which presented the following factors: educational level, economic income, kinds of diseases, household register, marital status, seeing and hearing, fall, pain ,social participation, alcohol drinking, whether live with relatives[16]. Another research listed the most influencing factors with a sequence of influence power as follow: economic support, gender, age, 
household register, marital status, social communication, income of children, family size and occupation[17].

6.Some other studies about QOL of elder people in China

One research used QOL scale, Self-Rating Anxiety Scale, Center for Epidemiologic Studies Depression Scale, Mini Mental State Examination and general condition questionnaire to analyze the factors that influence QOL of elders. It showed that the biggest influencing factors were depression, marital status and cognitive state. Another research showed that exercise amount was relative with QOL which was not linear. When the exercise amount went between 240-300min/week the correlation was strongest. When the exercise amount went between 150-240min/week there was a linear relation. But when the exercise amount went longer than 300min/week, QOL decreased[18]. A study controlled the variables like gender, age, income, social strata and education level, the richness, participation and complexity of social communication had significantly influence on subjective well-being of elders[19].

II .Modifications of evaluation methods based on new technique

1. We classified the factors that influence QOL of elders most referring to the researches above using classical QOL evaluations(Table 1) into: 1.physiologic factors; 2.mental factors; 3.social factors. Every of the three kinds of factors have cross affect over the others. As the evaluation system being in use, other factors collected by intelligent wearable devices which affect QOL strongly will be included into the system.

2. Using different kinds of intelligent wearable devices, most of the data about the factors that have been suggested to influence QOL of elders can be collected for the evaluation.

3. System with time attributes to make it a more accurate and multi-dimensional evaluation method. As social insurance and household registration system have not been intelligently reformed yet, some data are not available using intelligent wearable devices like chronic diseases and income which need to be input by the elders or their relatives.

4. The evaluation results are saved as data in the server's database and calculated continuously in order to identify how a factor affects the QOL result in individual or in group. The calculation process is dynamic with good growth.

III. The vitality index for elderly people and its calculation process

1. The concept of 'vitality index'

The 'vitality index' is defined as an index that reflect the general situation of the elders' lives which use intelligent wearable devices to collect data about every part of the elders' lives. Other than the general evaluation, it analyzes the relationship among the total index and all the factors of evaluation in individual and in group in order to find how much do the factors affect QOL for the particular individual or group, which is meaningful for the individual, the family members and the pension policy makers to take targeted adjustments to enhance the 'vitality index' for the elders. The 'vitality index' can also do well in remote intelligent monitoring for elders in order to enhance the safety for them of living alone and reduce the manpower and material consume.

2. Data collection

The factors to evaluate the 'vitality index' are classified into 3 groups: physiologic factors, mental factors and social factors. Most of the factors are collected using intelligent wearable devices, the factors that can't be collected intelligently yet are input using intelligent devices by the participant or his/her relative.

\section{Calculation Process}

The dimensions and orders of the data we collect are different from each other, which need to go through de-dimensional process before being synthesized. After consulting the specialists, the 
indexes can be divided into qualitative indexes and quantitative indexes, which are then divided into 3 types: linear type, broken linear type and curve type. The indexes are treated with standard de-dimension judging by the characteristics of the factor. The negative factors are fixed by using factor analysis, then the value of the negative factors are transformed into negative number to be made positive.

Exploratory factor analysis(EFA) and confirmatory factor analysis(CFA) are used to confirm the relationship of the factors which are included and not yet included in the evaluation and how the factors influence the vitality index. For individual the analyses are done to the data collected in different times to know the weight of the factors to one's life, so a specific QOL formula is done for him/her. Firstly EFA is done to inspect load of the factors and to describe a analysis model containing shadowed variables. For CFA we use generalized least squares method in order to confirm the model's rationality and to evaluate the load of the shadowed variables.

Finally the Vitality Index is calculated by using the weighted formula for the specific individual.

Table 1 Frequency of the factors that influence QOL of elders most being listed in recent researches

\begin{tabular}{ll}
\hline Factor & Frequency \\
\hline Chronic diseases & 6 \\
\hline Income & 4 \\
\hline Age & 3 \\
\hline Education level & 3 \\
\hline Medical insurance & 3 \\
\hline Social communication & 3 \\
\hline Have spouse or not & 2 \\
\hline Health condition(self-rated) & 2 \\
\hline Occupation & 1 \\
\hline Sleeping & 1 \\
\hline Eating & 1 \\
\hline Social support & 1 \\
\hline Exercise & 1 \\
\hline
\end{tabular}

\section{Discussion}

Nowadays, the health measurements elders can easily get are limited in blood pressure, blood sugar, etc., which make elders to regard these isolated measurements as showing their total health condition and to pay too much attention on them. The Vitality Index evaluation system we design is not only a number ,but always a tool for the elderly people and their relatives to be concerned with their QOL and knowing what kind of activities in life is good for health. How the awareness about QOL affect the elders' health will by studied next.

The Vitality Index evaluation system is based on a set of intelligent wearable devices and communication networks, which need a lot of investment in early period which may be a big problem for the system to be popular. On the other hand, most of the elderly people are unfamiliar with intelligent devices, which make it uneasy for them to get used to the devices. The intelligent wearable devices are required to be cheaper while easier to use and more comfortable for the elders to wear all day long, which is the most important for promoting the intelligent evaluation and monitoring method. 
Table 2 Hierarchical structure model of evaluation factors in Vitality Index

\begin{tabular}{|c|c|c|}
\hline & Group & Factor \\
\hline \multirow{21}{*}{ Quality of Life } & \multirow[t]{10}{*}{ Physical (A) } & Age $\left(\mathrm{A}_{1}\right)$ \\
\hline & & Gender $\left(\mathrm{A}_{2}\right)$ \\
\hline & & Blood pressure $\left(\mathrm{A}_{3}\right)$ \\
\hline & & Blood sugar $\left(\mathrm{A}_{4}\right)$ \\
\hline & & Blood fat $\left(\mathrm{A}_{5}\right)$ \\
\hline & & Breath $\left(\mathrm{A}_{6}\right)$ \\
\hline & & Heart rate $\left(A_{7}\right)$ \\
\hline & & Body temperature $\left(\mathrm{A}_{8}\right)$ \\
\hline & & Seeing $\left(A_{9}\right)$ \\
\hline & & Hearing $\left(\mathrm{A}_{10}\right)$ \\
\hline & \multirow[t]{4}{*}{ Mental (B) } & Cognition $\left(\mathrm{B}_{1}\right)$ \\
\hline & & $\operatorname{Mood}\left(\mathrm{B}_{2}\right)$ \\
\hline & & Appetite $\left(\mathrm{B}_{3}\right)$ \\
\hline & & Sleeping $\left(\mathrm{B}_{4}\right)$ \\
\hline & \multirow[t]{7}{*}{ Social (C) } & Education $\left(\mathrm{C}_{1}\right)$ \\
\hline & & Medical insurance $\left(\mathrm{C}_{2}\right)$ \\
\hline & & Occupation $\left(\mathrm{C}_{3}\right)$ \\
\hline & & Income $\left(\mathrm{C}_{4}\right)$ \\
\hline & & Marital status $\left(\mathrm{C}_{5}\right)$ \\
\hline & & Social communication $\left(\mathrm{C}_{6}\right)$ \\
\hline & & Exercise $\left(\mathrm{C}_{7}\right)$ \\
\hline
\end{tabular}

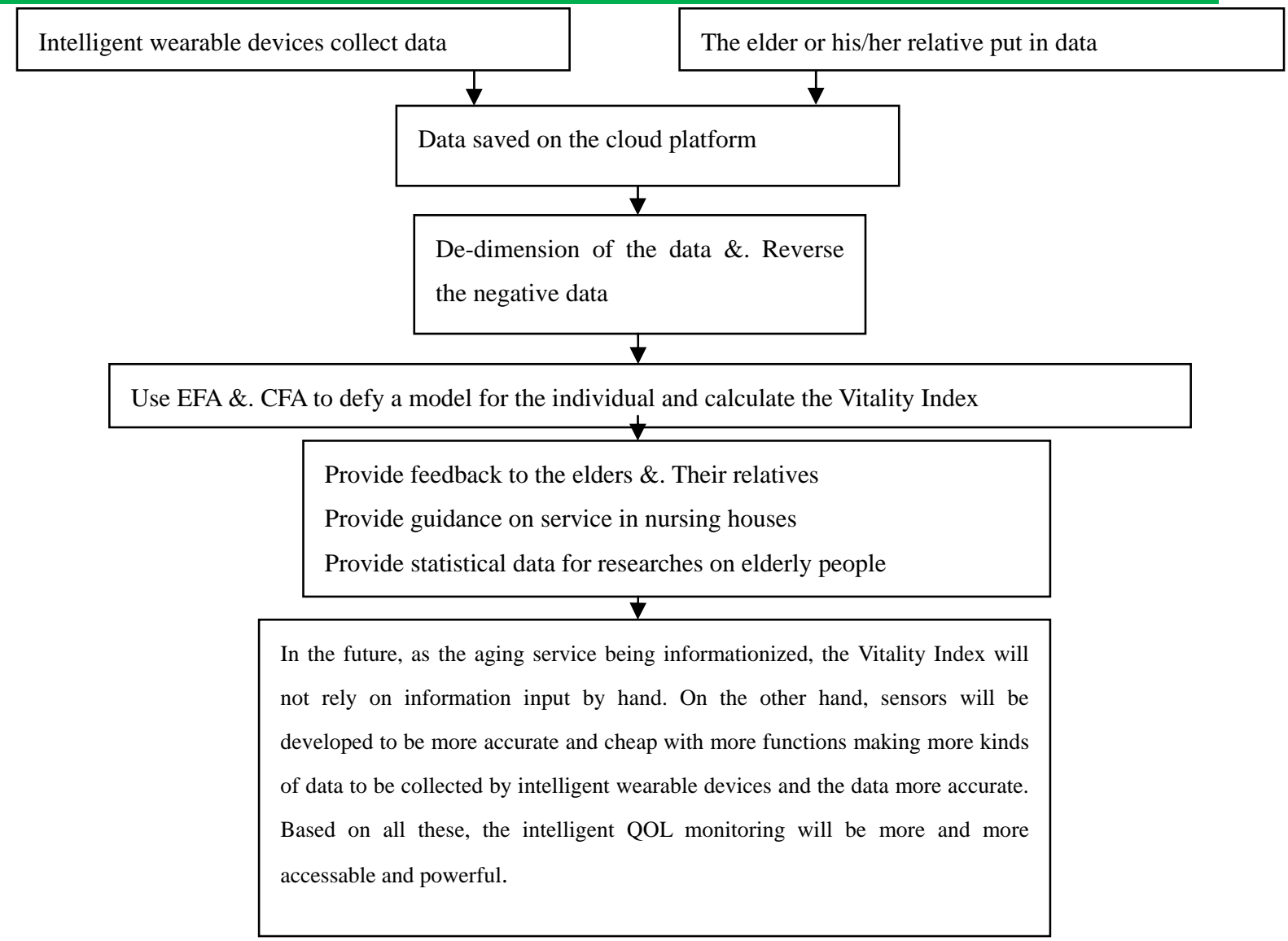

Fig. 1 The data process of Vitality Index 


\section{Reference}

[1] Information from National database of the National Bureau of statistics of the people's Republic of China.

[2] Q. Han, X. Shi, et al. The need of education based on investigation into current station of aging care nursing assistants, Basic medical education , (2016)18:1 pp71-73.

[3] W. Zijlstra, Mobility assessment in older people: new possibilities and challenges. Eur J Ageing, (2007)4:1 pp3-12.

[4] G. Demiris, B. Hensel, Senior residents' perceived need of and preferences for "smart home" sensor technologies. International Journal of Technology Assessment in Health Care, (2008)24:1, pp 120-124.

[5] O. Chipara, C. Lu, T. Bailey, G. Roman, Reliable clinical monitoring using wireless sensor networks: experiences in a step-down hospital unit. SenSys '10 Proceedings of the 8th ACM Conference on Embedded Networked Sensor Systems, pp 155-168.

[6] I. Back,J. Kallio, S. Perala, et al. Remote Monitoring of Home Residents Using a Humanoid Robot. Journal of medicine and Telecare,(2012)18:6 pp357-361.

[7] A. Sixsmith, N. Johnson, A Smart Sensor to Detect the fall of the elderly, IEEE Pervasive Computing,(2004)3:2 pp42-47.

[8] Y. Guo, Y. Li. A research of Life Quality with Prospect. Journal of Southern Medical University,(2001)21:6 pp464-6.

[9] J. Fang. The Evaluation Methods of Life Quality and Their Applications. Journal of Beijing Medical University,2000 pp49-53.

[10] Y. Gao, D. Chen, X. Zhuang, et al. Factor analysis of the determinants of quality of life of elders in Nantong. Chinese Journal of Gerontology, 2013,33 pp3928-3931.

[11] X. Hao, J. Liu, et al. Study on the influencing factors of the elderly health from the perspective of social support:based on empirical research in Beijing. China Health Economics, 2015,34:6 pp56-59.

[12]Y. Zhang, Y. Gui, et al. A Comparison of Life Quality of Elder People in Different Districts of China and Influencing Factors. Chinese Journal of Gerontology, 2013,9（33）pp4514-4515.

[13] Y. Zhang, Y. Gui, et al. Life Quality of Elder People Who Live Under Family Care Pattern in Different Districts of China and Influencing Factors. Chinese Journal of Gerontology, 2014,7 (34) pp3990-3992.

[14] J. Fang, D. Wu, Y. Fan. Research on influencing factors of quality of life of the empty-nesters in Lianhua Community in Hefei City. Medical Information.2015, 28(8) pp122-123.

[15] J. Zhou, X. Ma, Factors influencing quality of life of the elderly living at a nursing home of Shanghai. China Journal of Health Manage,2012,6(6):389-393.

[16]J. Liu. A Research of Life Satisfaction of Elder People in China and Influencing Factors-_ Basing on Analysis of Baseline Data of China in CHARLS of 2011.Scientific Research on Aging,2015, 3(1) pp69-78.

[17]X. Liu, J. Wang. Analyzing two-stage models of influencing factors on the elderly health status. Chinese Health Economics, 2013,32(10) pp51-53.

[18] J. Dai, X. Liu, et al. Quality of life and its related factors on quality of life of aged people. Chinese Journal of Clinical Psychology, 2002,10(4) pp 246-248.

[19] W. Li. Dose-response Relationships between Exercise Dose and HRQOL in Old People adults-an Epidemiological View. Journal of Chengdu Sport University,40(4) pp66-72. 